University of Texas Rio Grande Valley

ScholarWorks @ UTRGV

Psychological Science Faculty Publications and

Presentations

College of Liberal Arts

$10-19-2018$

\title{
Latent Classes of Lifetime Sexual Victimization Characteristics in Women in Emerging Adulthood: Differential Relations With Emotion Dysregulation
}

\author{
Ruby Charak \\ The University of Texas Rio Grande Valley, ruby.charak@utrgv.edu \\ David DiLillo \\ University of Nebraska - Lincoln \\ Terri L. Messman-Moore \\ Miami University \\ Kim L. Gratz \\ The University of Toledo
}

Follow this and additional works at: https://scholarworks.utrgv.edu/psy_fac

Part of the Psychology Commons

\section{Recommended Citation}

Charak, R., DiLillo, D., Messman-Moore, T., \& Gratz, K. (2018). Latent Classes of Lifetime Sexual Victimization Characteristics in Women in Emerging Adulthood: Differential Relations With Emotion Dysregulation. Psychology of Violence, 8(5), 570-579. https://doi.org/10.1037/vio0000154

This Article is brought to you for free and open access by the College of Liberal Arts at ScholarWorks @ UTRGV. It has been accepted for inclusion in Psychological Science Faculty Publications and Presentations by an authorized administrator of ScholarWorks @ UTRGV. For more information, please contact justin.white@utrgv.edu, william.flores01@utrgv.edu. 
APA Citation. Charak, R., DiLillo, D., Messman-Moore, T. L., \& Gratz, K. L. (2019). Latent classes of lifetime sexual victimization characteristics in women in emerging adulthood: Differential relations with emotion dysregulation. Psychology of Violence, 8, 570-579.

doi.http://dx.doi.org/q0.1037/vio0000154

Note. The following document is the final version of the accepted manuscript (Post peerreview; before the proof-reading stage). It may differ from the published article. 


\title{
Latent Classes of Lifetime Sexual Victimization Characteristics in Women in Emerging Adulthood: Differential Relations With Emotion Dysregulation

\author{
Ruby Charak \\ University of Texas Rio Grande Valley \\ Terri L. Messman-Moore \\ Miami University
}

\author{
David DiLillo \\ University of Nebraska—Lincoln \\ Kim L. Gratz \\ University of Toledo
}

\begin{abstract}
Objectives: The aims of the present study were to investigate latent classes of sexual victimization among young adult women based on characteristics of their victimization experiences (e.g., relationship with the perpetrator, nature of act, and frequency) and examine differences in dimensions of emotion dysregulation across these classes and among nonvictims. Method: Participants were 491 women in the age range of 18-25 years from the United States; of these, 335 participants $(M=22.0, S D=2.22)$ reported at least one experience of sexual victimization during their lifetime. Latent class analysis was used to identify groups of women based on characteristics of their sexual victimization experiences. Results: A 3-class solution was found to be most parsimonious. The classes were labeled as high-severity developmental revictimization (DRV; 43.3\%), low-severity child/adolescent sexual abuse (CASA; 20.3\%), and lowseverity adult sexual assault (ASA; $36.4 \%$ ). The DRV class reported higher rates of penetrative abuse and longer duration of abuse than the CASA class, and higher rates of injury during assault than the ASA class. Further, the DRV class reported greater difficulties in 3 dimensions of emotion regulation than the ASA class and greater deficits in emotional clarity than the CASA class. Finally, the 3 latent classes reported greater difficulties in at least 4 dimensions of emotion regulation than the nonvictimized group. Conclusions: Findings of different classes of sexual victimization suggest the multidimensionality of these experiences. Results also highlight the potential utility of interventions aimed at improving emotion regulation among women with severe childhood sexual abuse.
\end{abstract}

Keywords: sexual victimization characteristics, sexual revictimization, LCA, emotion dysregulation, women

Sexual violence is a major public health concern associated with an array of adverse behavioral, cognitive, interpersonal, and emotional outcomes (Messman-Moore, Walsh, \& DiLillo, 2010; Messman-Moore, Ward, \& Zerubavel, 2013; Navalta, Polcari, Webster, Boghossian, \& Teicher, 2006). Women are disproportionately affected by sexual violence (Black et al., 2011). Further, although sexual assault may happen at any age, the developmental period between ages 18 and 25 (known as emerging adulthood; Arnett, 2000) is a particularly high-risk time for incidents of sexual assault (Black et al., 2011).

Ruby Charak, Department of Psychological Science, University of Texas Rio Grande Valley; David DiLillo, Department of Psychology, University of Nebraska-Lincoln; Terri L. Messman-Moore, Department of Psychology, Miami University; Kim L. Gratz, Department of Psychology, University of Toledo.

Correspondence concerning this article should be addressed to Ruby Charak, Department of Psychological Science, University of Texas Rio Grande Valley, Liberal Arts Building North 361, Edinburg, TX 78539. E-mail: ruby.charak@utrgv.edu

\section{Sexual Victimization: A Multidimensional Phenomenon}

Studies examining sexual victimization often treat these experiences as homogeneous constructs rather than multifaceted phenomena encompassing a range of characteristics that vary with regard to severity and consequences (e.g., age of onset, nature of victimization, duration, frequency, and relationship with the perpetrator). Of the relatively few studies that have investigated the role of characteristics of victimization experiences, most assess only one or two characteristics; for example, Allen (2008) examined the differential impact of specific forms of childhood psychological abuse (including being terrorized by a caregiver, degradation, ignoring, and isolating) on psychopathology constructs. Results revealed that different forms of maltreatment maybe differentially related to the development of emotional and behavioral problems. In another study, earlier age of onset of maltreatment (any type) was found to be associated with anxiety and depression, whereas later age of onset was predictive of more behavioral problems in adulthood (Kaplow \& Widom, 2007). Taken together, these studies suggest that different characteristics of abuse may have relevance for the consequences and associated difficulties of 
CHARAK, DILILLO, MESSMAN-MOORE, AND GRATZ

these experiences, and that sexual victimization may be best conceptualized as a multifaceted phenomenon encompassing a range of acts involving unwanted sexual contact (e.g., touching/fondling, kissing, and acts of oral, anal, or genital penetration) that vary in frequency, duration, tactics used by the perpetrator (e.g., verbal coercion, physical force, and threat of physical harm), and the victim's relationship with the perpetrator.

Indeed, knowledge of specific victimization characteristics provides rich descriptive information about sexual assault experiences and may improve understanding of postassault functioning (Steel, Sanna, Hammond, Whipple, \& Cross, 2004). For example, Mennen and Meadow (1994) found greater symptoms of depression and lower self-worth in childhood survivors of extrafamilial sexual abuse, relative to survivors of intrafamilial abuse. Likewise, Ruggiero, McLeer, and Dixon (2000) found that several assault characteristics, including older age at abuse onset, greater frequency and duration of sexual abuse, and perpetration by someone other than a father figure, were associated with a greater number of avoidance behaviors in children. These findings support the heterogeneity of sexual victimization experiences and their differential relations with psychological outcomes.

\section{Role of Sexual Revictimization as Defined Across Developmental Periods}

One victimization characteristic that may be particularly important to consider is sexual revictimization, defined as the experience of sexual abuse or assault across two or more developmental periods (e.g., childhood, adolescence, and adulthood; Arata, 2000; Classen, Palesh, \& Aggarwal, 2005; Macy, 2008; Messman-Moore $\&$ Long, 2003). Many studies have documented the cumulative and detrimental impact of sexual revictimization across two different developmental periods on the psychological well-being of young women (see Arata, 2000; Humphrey \& White, 2000). For example, in a study of female undergraduates, Arata (2000) found higher levels of self-blame, posttraumatic stress symptoms, and high-risk sexual behavior among women with both childhood sexual victimization and adolescent or adult sexual victimization experiences (i.e., sexual revictimization), compared with those with childhood sexual abuse experiences only. Similarly, in three nationally representative samples of adolescent girls, college women, and community women, Walsh, Danielson, et al. (2012) found that the likelihood of meeting criteria for past 6-month posttraumatic stress disorder was four to eight times higher among females with sexual revictimization and two to four times higher among those with a single victimization experience, compared with females without a history of sexual victimization. Notably, the Walsh, Danielson, et al. (2012) study defined sexual revictimization as two or more sexual assaults across the life span that may entail either sexual revictimization across different developmental periods (i.e., childhood, adolescence, and adulthood) or two or more victimization experiences in a single developmental period. In contrast, and in light of literature supporting the particular relevance of experiences of sexual assault across two or more developmental periods (see Arata, 2000; Humphrey \& White, 2000), the current study focuses specifically on sexual revictimization, and conceptualizes sexual revictimization as sexual victimization across two developmental periods (childhood/adoles- cence and adulthood), henceforth referred to as developmental revictimization.

\section{Sexual Victimization and Emotion Regulation Difficulties}

Researchers posit that one common factor underlying the diverse psychological sequelae of sexual victimization (and revictimization) is emotion regulation difficulties (Gratz, Weiss, \& Tull, 2015). A multifaceted construct, emotion regulation encompasses the awareness, understanding, and acceptance of emotions; ability to control behaviors when experiencing distress; and the ability to use contextually appropriate emotion regulation strategies flexibly to modulate emotions (Gratz \& Roemer, 2004). The capacity for emotion regulation begins to develop early in life when dyadic interactions between the caregiver and child help build the child's repertoire of emotion regulation skills (Calkins \& Howse, 2004). Disruptions in these early relationships (e.g., through sexual victimization), in the absence of other protective factors, can increase risk for disruptions in emotion-regulatory abilities (Cole, Michel, \& Teti, 1994; Cicchetti, Ganiban, \& Barnett, 1991). Supporting this premise, research shows that survivors of childhood sexual abuse exhibit poorer emotion regulation skills (Cicchetti et al 1991) than their nonmaltreated counterparts, and that these diffi $\Omega$ culties continue to manifest in adulthood (Cloitre, Miranda, Stovall-McClough, \& Han, 2005; Gratz, Bornovalova, DelanyBrumsey, Nick, \& Lejuez, 2007). Moreover, evidence suggests AQ: 3 that emotion regulation is not a stable trait—an individual's capacity for adaptive emotion regulation can be influenced by a number of experiences (e.g., traumatic events and treatment) across the life span (John \& Gross, 2004), including revictimization experiences (Walsh, DiLillo, \& Scalora, 2011). Indeed, recent findings suggest a cumulative impact of developmental revictimization (relative to victimization experiences in either childhood or adulthood) on emotion regulation deficits (Walsh et al., 2011). Research examining the relation of specific victimization (and developmental revictimization) characteristics to different emotion regulation difficulties may help elucidate at-risk groups of women and inform the development of targeted interventions for specific victimization experiences.

\section{The Current Study}

Although abuse characteristics appear to play an important role in victims' psychological responses to sexual victimization, few studies have taken these characteristics into account. As a result, individuals with diverse victimization experiences are often examined as a single (presumably homogeneous) group, which may blur important distinctions across victims' experiences. To address this gap, we used latent class analysis to classify women on the basis of a number of lifetime sexual victimization characteristics. First, although exploratory, we expected that at least one latent class would be consistent with the extant literature documenting the occurrence of developmental revictimization (Arata, 2000; Messman-Moore \& Long, 2003). Second, on the basis of previous studies suggesting a cumulative impact of developmental revictimization on emotion regulation difficulties (Walsh, Danielson, et al., 2012; Walsh et al., 2011), we expected that class(es) with a higher proportion of women reporting developmental revictimiza- 
tion experiences would report greater difficulties in emotion regulation dimensions than classes characterized by victimization in only childhood or adulthood. Third, we expected that all latent classes characterized by sexual victimization would be higher on all dimensions of emotion regulation difficulties than nonvictims of sexual assault.

\section{Method}

\section{Participants}

Participants were part of a multisite longitudinal study on emotion dysregulation and sexual revictimization among young adult women. Participants were recruited from the community at four sites in the United States, namely, Lincoln and Omaha (Nebraska), Oxford (Ohio), and Jackson (Mississippi). Data for the present study were drawn from the larger sample of $491(M=21.7, S D=$ 2.23) women who completed Wave 1 of the longitudinal study. However, to be included in the latent class analysis, participants had to have reported at least one instance of sexual victimization in childhood/adolescence and/or adulthood. This led to the selection of 335 participants ranging in age from 18 to 25 years $(M=$ $22.0, S D=2.22$ ). Self-reported racial/ethnic background of these 335 participants was $64.2 \%$ White, $32.5 \%$ African American, $6.6 \%$ Latina, 5.1\% Asian, 3.6\% American Indian, and 2.7\% other (categories were not mutually exclusive, so total exceeds $100 \%$ ). The remaining 156 women without a reported history of sexual victimization were $55.1 \%$ White, $40.4 \%$ African American, $3.8 \%$ Latina, 2.6\% Asian, and 1.9\% American Indian.

\section{Procedures}

The institutional review boards of all participating institutions approved the study procedures. A list of potential participants who fulfilled the eligibility criteria (i.e., women in the age range of 18-25 years and from the study site locations) was identified through Survey Sampling International. Recruitment letters were sent to randomly selected women from this list. In addition, participants were recruited via community advertisements. In all cases, participants were recruited for a study on "life experiences and adjustment among young adult women," without any mention of a focus on sexual victimization experiences. All participants provided written informed consent. Each participant was compensated $\$ 75$ for the Wave 1 assessment.

\section{Measures}

Childhood and adolescent sexual abuse. Childhood sexual abuse characteristics were assessed via the Computer-Assisted Maltreatment Inventory-Sexual Abuse (CAMI-SA; DiLillo et al., 2010). The CAMI-SA is a web-based self-report measure that assesses history of childhood maltreatment from adult respondents. Here, only the Sexual Abuse (SA) subscale was used. To screen for child or adolescent sexual abuse, participants were presented with a list of sexual acts varying in severity (e.g., kissing, fondling, and intercourse) and asked to indicate whether, before the age of 18 , they experienced any of these unwanted acts (a) against their will, (b) with a family member, or (c) with someone at least 5 years older. Participants were asked to exclude experiences that occurred during explorative play with a peer or voluntary acts with a dating partner. Participants who responded affirmatively to one or more screener items were then asked to select from a list of 41 possible perpetrators up to five individuals (i.e., perpetrators) with whom these events occurred. They were then directed to a series of detailed follow-up questions assessing specific characteristics of their experiences, including the age of onset; nature, frequency, and duration of the activities; degree of force and types of manipulation involved; relationship with the perpetrator; and number of perpetrators. The criterion-related validity of the CAMI-SA with the Sexual Abuse subscale of Childhood Trauma Questionnaire (Bernstein et al., 2003) has been found to be adequate in a sample of 1,195 undergraduate students, with $92.4 \%$ classified consistently across the two measures (DiLillo et al., 2006, 2010). The test-retest reliability of research-defined sexual victimization status on this measure across a span of 2-4 weeks was .74.

The SA-specific characteristics assessed on the CAMI include the following: age of onset (childhood [0-11 years] $=1$, adolescence $[12-17$ years] $=2$ ), relationship to the perpetrator (nonfamily $=1$, family nonparent $=2$, parent $=3$ ), frequency of abusive acts $(1-2$ times $=1,3-10$ times $=2,>10$ times $=3)$, nature of the acts $($ contact/no penetration $=1$, penetration $=2)$, duration of activities $(<1$ year $=1,1-2$ years $=2,>2$ years $=3)$, use of force/tactics (verbal $=1$, threat of physical harm $=2$, physically held down $=3$, no force $=4$ ), and number of perpetrators (one $=$ 1 , two $=2$, three or more $=3$ ). Scores for each characteristic were then summed to produce a total severity score that was used to inform the selection of the sexual abuse experience and related characteristics to be included in analyses for participants with multiple perpetrators. Specifically, for participants reporting multiple perpetrators, the seven abuse characteristics (i.e., age of onset, relationship to the perpetrator, frequency of abusive acts, nature of the acts, duration of activities, use of force/tactics, and number of perpetrators) from the perpetrator with the highest total severity score were included in the present analysis. If participants reported abuse experiences with identical severity scores across multiple perpetrators, the characteristics of one of those experiences were randomly selected for analysis. Finally, participants who reported no experiences of sexual abuse were coded as 0 .

Adult sexual assault. The Modified Sexual Experience Survey (MSES; Messman-Moore, Long, \& Siegfried, 2000; MessmanMoore et al., 2010) was used to assess the presence and characteristics of adult sexual assault experiences. The MSES assesses unwanted sexual experiences since a participant's 18th birthday. Participants in the present study were asked a number of follow-up questions about the adulthood assault (by a male perpetrator[s]) they identified as most distressing. These questions asked for information about the nature of the act (contact and/or penetration), relationship to the perpetrator (intimate and/or nonintimate), force used during the assault (threat and/or verbal and/or intoxication), and injury/physical pain. The nature of the act and relationship to the perpetrator were dichotomized ( No $=1$, Yes $=2$ ), whereas force and injury/physical pain were rated on a 5-point Likert-type scale ranging from 1 (not at all) to 5 (very much). To dichotomize the latter two variables for the purpose of analysis in the present study, responses of not at all (i.e., a score of 1) were coded as 1, and responses of 2 or greater were coded as 2 . Participants who did not endorse sexual assault during adulthood were coded as 0 . 
Emotion dysregulation. Difficulties in emotion regulation were measured through the Difficulties in Emotion Regulation Scale (DERS; Gratz \& Roemer, 2004). The DERS is a 36-item self-report questionnaire assessing individuals' typical levels of emotion dysregulation across six domains: nonacceptance of emotional responses, difficulties engaging in goal-directed behaviors when distressed, difficulties controlling impulsive behaviors when distressed, lack of emotional awareness, limited access to effective emotion regulation strategies, and lack of emotional clarity. The DERS has demonstrated good psychometric properties in clinical and community samples (Fowler et al., 2014; Gratz \& Roemer, 2004). In the present study, the Cronbach's $\alpha$ for each of the six subscales of the DERS was acceptable ( $\alpha \mathrm{s}=.84$ to .93 ).

\section{Analytic Approach}

Latent class analysis (LCA) was conducted using Mplus 7.11 software (Muthén \& Muthén, 2013) to achieve the first aim of the present study. LCA is a person-centered analytic approach that uses maximum likelihood estimation with robust standard errors to classify participants into discrete latent classes. Assignment of a participant to a latent class is probabilistic based on similar response patterns to a series of items measuring characteristics of child/adolescent sexual abuse and adult sexual assaults assessed via the CAMI-SA and MSES, respectively. In the present study, the following items were included in the LCA: from the CAMISA, age of onset, relationship to the perpetrator, frequency of abusive acts, nature of the acts, duration of activities, use of force/tactics, and number of perpetrators; similarly, from the MSES, nature of the act (contact and/or penetration), relationship to the perpetrator (intimate and/or nonintimate), force used during the assault (threat and/or verbal and/or intoxication), and injury/ physical pain. All participants with a history of sexual victimization $(N=335)$ were included in the analysis regardless of whether they did or did not endorse a particular sexual victimization characteristic.

Selection of the number of classes was based on interpretive meaningfulness and statistical relevance. With respect to the model fit, a series of goodness-of-fit indices were examined, including the Lo-Mendell-Rubin adjusted likelihood ratio test (LMR; Lo, Mendell, \& Rubin, 2001), bootstrapped likelihood ratio test (McLachlan \& Peel, 2000), the Bayesian information criterion (BIC; Schwarz, 1978), sample size-adjusted Bayesian information criterion (SSABIC; Sclove, 1987), and the entropy value (Ramaswamy, DeSarbo, Reibstein, \& Robinson, 1993). The LMR and the bootstrapped likelihood ratio test use likelihood ratio tests to determine whether a model with one fewer latent class fits significantly better than the target model (e.g., whether a two-class solution fits the data better than a three-class solution). Additionally, the BIC and the SSABIC help determine the optimal number of classes, with lower values indicating more suitable solutions. Finally, when the number of classes is specified, the entropy value shows the accuracy of class assignments, with values closer to 1 suggesting more accurate class assignment or classification. The present study considered all these statistical indices to select the optimal number of latent sexual victimization classes from the two- to four-class solution. The obtained latent classes were exported into IBM SPSS software version 23.0 for further analyses.
After obtaining the latent classes, between-group differences in racial/ethnic background (defined as White vs. non-White, African American vs. non-African American, Asian vs. non-Asian, American Indian vs. non-American Indian, Latina vs. non-Latina) were assessed via chi-square analyses, and the adjusted residuals were further examined. Next, between-group differences in victimization characteristics (e.g., nature of unwanted acts and presence of force) were examined using chi-square analyses to label and describe each emergent class. Further, the adjusted residuals were used to examine the significance of each cell. A value of +2 or above on the adjusted residuals is deemed significant, with the observed frequency being significantly greater than the expected frequency. Similarly, a value of -2 or lesser on the adjusted residuals is deemed significant, with the observed frequency being significantly lesser than the expected frequency. Finally, differences across the latent classes and the group with no reported sexual victimization experiences (i.e., nonvictims) on the six dimensions of difficulties in emotion regulation were examined using a multivariate analysis of covariance controlling for race (White vs. non-White), with follow-up univariate analyses of covariance and pairwise comparisons using a Bonferroni correction term to examine specific between-group differences on each of the emotion regulation difficulties. Because there were 18 comparisons in the present study, the new Bonferroni-adjusted $\alpha$ level of .003 ( $\alpha=$ $.05 / 18$ ) was used to test the level of significance per comparison.

\section{Results}

\section{Number of Latent Classes Based on Characteristics of Sexual Victimization}

Results of the LCA indicated a three-class solution as the best solution based on a number of goodness-of-fit indices (see Table 1) T1 and conceptual meaningfulness of the classes. Participants were assigned to a certain latent class based on the probability of being in that class. The likelihood ratio test (i.e., the LMR) and the BIC clearly favored the three-class solution, in contrast to the SSABIC that suggested a four-class solution. We prioritized the information provided by the BIC, given that the SSABIC tends to overestimate the number of classes (Nylund, Asparouhov, \& Muthén, 2007). Finally, entropy was high and the average posterior probability for most likely class membership ranged from .989 to .993 for the three-class solution, suggestive of excellent class determination. Thus, based on statistical and conceptual relevance, the three-class solution was chosen.

\section{Labeling of the Latent Classes and Differences in Characteristics of Sexual Victimization}

The classes were labeled according to the presence of sexual victimization during childhood/adolescence and adulthood, as well as victimization characteristics. Class $1(N=145)$ was labeled high-severity developmental revictimization (DRV), as all women in this class had experienced sexual victimization during two developmental periods (i.e., before and after age 18). Adjusted residuals $\geq+2$ indicated that in contrast to the other classes, the DRV class had a significantly higher proportion of women endorsing penetrative child/adolescent sexual abuse, longer duration ( $>2$ years) of sexual abuse during childhood and adolescence (see Table 2), and physical injury and pain during adulthood sexual T2 
Table 1

Fit Indices for the Latent Class Models With Two to Four Classes for Lifetime Sexual Victimization Experiences Among Women in Emerging Adulthood

\begin{tabular}{cccccc}
\hline Number of classes & LMR $(p$ value $)$ & BLRT $(p$ value $)$ & Entropy & BIC & SSABIC \\
\hline 2 & $3,132.75(.001)$ & $-5,393.28(.001)$ & .99 & $8,063.68$ & $7,832.12$ \\
3 & $1,824.58(.001)$ & $-3,819.62(.001)$ & .98 & $6,445.74$ & $6,096.81$ \\
4 & $121.98(.11)$ & $-2,903.09(.001)$ & .93 & $6,538.31$ & $6,072.01$ \\
\hline
\end{tabular}

Note. $\quad$ LMR $=$ Lo-Mendell-Rubin test; BLRT $=$ bootstrapped likelihood ratio test BIC $=$ Bayesian information criterion; SSABIC $=$ sample size-adjusted Bayesian information criterion.

assault (see Table 3). Class $2(N=68)$ was labeled low-severity child/adolescent sexual abuse (CASA), as all women in this class reported sexual abuse in either childhood or adolescence and endorsed relatively less severe abuse characteristics than the DRV class. Specifically, relative to the DRV class, the CASA class had significantly more women with contact experiences (e.g., fondling) and no penetration, and a duration of victimization of $<1$ year (i.e., adjusted residuals $=4.3$ and 3.65, respectively; see Table 2). Class $3(N=122)$ was labeled low-severity adult sexual assault (ASA), as all women in this class reported sexual victimization during

Table 2

Percentage Distribution of Sexually Victimized Women Across Relevant Latent Classes as a Function of Specific Childhood/ Adolescence Sexual Abuse Characteristics

\begin{tabular}{|c|c|c|c|}
\hline $\begin{array}{l}\text { Childhood/adolescence sexual } \\
\text { abuse characteristics }\end{array}$ & $\begin{array}{l}\text { Class 1: DRV \% } \\
\text { (Adj. residual }^{\mathbf{a}} \text { ) }\end{array}$ & $\begin{array}{l}\text { Class 2: CASA \% } \\
{\left(\text { Adj. } \text { residual }^{\mathrm{a}}\right)}^{\text {(n) }}\end{array}$ & $x^{2}$ \\
\hline \multicolumn{4}{|l|}{ Age of onset } \\
\hline Childhood (0-11years) & 50.2 & 48.8 & \multirow[t]{2}{*}{.06} \\
\hline Adolescence (12-17 years) & 49.8 & 51.2 & \\
\hline \multicolumn{4}{|l|}{ Relation with perpetrator } \\
\hline Nonfamily & 59.6 & 65.7 & \multirow{3}{*}{.75} \\
\hline Family nonparent & 27.8 & 23.6 & \\
\hline Parent & 12.6 & 10.7 & \\
\hline \multicolumn{4}{|l|}{ Frequency } \\
\hline 1-2 times & 32.1 & 47.1 & \multirow[t]{3}{*}{.09} \\
\hline 3-10 times & 32.7 & 30.0 & \\
\hline$>10$ times & 35.2 & 23.0 & \\
\hline \multicolumn{4}{|l|}{ Nature of the act } \\
\hline Contact/No penetration & $30.4 /-2.95$ & $50.4 / 4.3$ & \multirow[t]{2}{*}{$6.88^{* * *}$} \\
\hline Penetration & $69.6 / 2.3$ & $49.6 /-3.3$ & \\
\hline \multicolumn{4}{|l|}{ Duration } \\
\hline$<1$ year & $43.3 /-2.5$ & $62.1 / 3.65$ & \multirow[t]{3}{*}{$6.23^{*}$} \\
\hline $1-2$ years & $18.5 / 1.25$ & $13.0 /-1.85$ & \\
\hline$>2$ years & $38.2 / 2.15$ & $24.9 /-3.13$ & \\
\hline \multicolumn{4}{|l|}{ Force } \\
\hline No CASA & 0 & 0 & \multirow{5}{*}{7.62} \\
\hline Verbal & 31.5 & 22.4 & \\
\hline Threat of physical harm & 7.1 & 14.0 & \\
\hline Physically held down & 51.2 & 43.9 & \\
\hline No force & 10.1 & 19.8 & \\
\hline \multicolumn{4}{|l|}{ Number of perpetrators } \\
\hline One & 52.1 & 63.7 & \multirow[t]{3}{*}{2.21} \\
\hline Two & 23.3 & 17.9 & \\
\hline Three or more & 24.5 & 18.3 & \\
\hline
\end{tabular}

Note. Class $1=$ high-severity developmental revictimization (DRV: $N=$ 145); Class $2=$ low-severity child/adolescent sexual abuse (CASA; $N=$ $68)$.

${ }^{a}$ Adjusted (Adj.) residual variance is reported only if chi-square is significant.

${ }^{*} p<.05 . \quad{ }^{* *} p<.01$. adulthood only (i.e., after age 18) and endorsed relatively less severe victimization characteristics (e.g., physical injury or pain) than the DRV class (i.e., adjusted residuals $=-20.11$; see Table 3 ). Thus, these classes provide support for the first hypothesis, revealing a separate class of women reporting developmental revictimization (vs. child/adolescence or adult victimization alone).

\section{Between-Group Differences in Racial/Ethnic Background}

As shown in Table 4, results revealed significant differences T4 among the three classes and the nonvictim group in White (vs.

Table 3

Percentage Distribution of Sexually Victimized Women Across Relevant Latent Classes as a Function of Specific Adulthood Sexual Assault Characteristics

\begin{tabular}{|c|c|c|c|}
\hline $\begin{array}{l}\text { Adulthood sexual assault } \\
\text { characteristics }\end{array}$ & $\begin{array}{l}\text { Class 1: DRV \% } \\
\left(\text { Adj. residual }^{\mathrm{a}} \text { ) }\right.\end{array}$ & $\begin{array}{l}\text { Class 3: ASA \% } \\
{\left(\text { Adj. residual }^{\mathrm{a}} \text { ) }\right.}^{\text {Ad }}\end{array}$ & $x^{2}$ \\
\hline \multicolumn{4}{|l|}{ Nature of the act } \\
\hline \multicolumn{4}{|l|}{ Fondling/kissing } \\
\hline Absent & 13.9 & 21.9 & \multirow[t]{2}{*}{3.18} \\
\hline Present & 86.1 & 78.1 & \\
\hline \multicolumn{4}{|l|}{ Penetration } \\
\hline Absent & 13.9 & 18.6 & \multirow[t]{2}{*}{1.26} \\
\hline Present & 86.1 & 81.4 & \\
\hline \multicolumn{4}{|l|}{ Relation with perpetrator } \\
\hline Intimate & & & \\
\hline Absent & 52.4 & 52.9 & \multirow{2}{*}{.02} \\
\hline Present & 47.6 & 47.1 & \\
\hline \multicolumn{4}{|l|}{ Nonintimate } \\
\hline Absent & 44.7 & 40.5 & \multirow[t]{2}{*}{.44} \\
\hline Present & 55.3 & 59.5 & \\
\hline \multicolumn{4}{|l|}{ Force used } \\
\hline Verbal coercion & & & \multirow{3}{*}{2.23} \\
\hline Absent & 18.5 & 26.3 & \\
\hline Present & 81.5 & 73.7 & \\
\hline \multicolumn{4}{|l|}{ Intoxication } \\
\hline Absent & 54.6 & 52.9 & \multirow[t]{2}{*}{.04} \\
\hline Present & 45.4 & 47.1 & \\
\hline \multicolumn{4}{|l|}{ Threaten/Held-down } \\
\hline Absent & 19.0 & 24.1 & \multirow[t]{2}{*}{.79} \\
\hline Present & 81.0 & 75.9 & \\
\hline \multicolumn{4}{|l|}{ Injury/Physical pain } \\
\hline Absent & $39.5 /-18.66$ & $61.6 / 20.33$ & $14.0^{* * * *}$ \\
\hline Present & $60.5 / 18.44$ & $38.4 /-20.11$ & - \\
\hline
\end{tabular}

Note. Class $1=$ high-severity developmental revictimization $(\mathrm{DRV} ; N=$

145 ); Class $3=$ low-severity adulthood sexual assault (ASA; $N=122$ ).

${ }^{\text {a }}$ Adjusted residual variance is reported only if chi-square is significant.

***** $p<.001$. 
Table 4

Percentage Distribution of Sexually Victimized Women Across the Three Classes and the Nonvictimized Group as a Function of Racial/Ethnic Background

\begin{tabular}{|c|c|c|c|c|c|}
\hline $\begin{array}{l}\text { Racial/Ethnic } \\
\text { background }\end{array}$ & $\begin{array}{c}\text { Class 1: DRV \% } \\
\text { (Adj. residual }^{a} \text { ) }\end{array}$ & $\begin{array}{c}\text { Class 2: CASA \% } \\
\left.{\left(\text { Adj. }^{2} \text { residual }\right.}^{\text {a }}\right)\end{array}$ & $\begin{array}{l}\text { Class 3: ASA \% } \\
\text { (Adj. residual }^{\mathrm{a}} \text { ) }\end{array}$ & $\begin{array}{c}\text { NV \% } \\
\text { (Adj. residual }^{\mathrm{a}} \text { ) }\end{array}$ & $x^{2}$ \\
\hline \multicolumn{6}{|l|}{ Latina } \\
\hline Yes & 5.6 & 10.3 & 5.7 & 3.8 & \multirow[t]{2}{*}{3.65} \\
\hline No & 94.4 & 89.7 & 94.3 & 96.2 & \\
\hline \multicolumn{6}{|l|}{ White } \\
\hline Yes & $65.5 / 1.2$ & $45.6 /-2.9$ & $73.0 / 3.0$ & $55.1 /-1.9$ & \multirow[t]{2}{*}{$17.65^{* * * *}$} \\
\hline No & $34.5 /-1.2$ & $54.4 / 2.9$ & $27.0 /-3.0$ & $44.9 / 1.9$ & \\
\hline \multicolumn{6}{|l|}{ African American } \\
\hline Yes & $31.0 /-1.2$ & $44.1 / 1.7$ & $27.9 /-1.9$ & $59.6 /-1.7$ & \multirow[t]{2}{*}{$8.2^{*}$} \\
\hline No & $69.0 / 1.2$ & $55.9 /-1.7$ & $72.1 / 1.9$ & $40.4 / 1.7$ & \\
\hline \multicolumn{6}{|l|}{ Asian } \\
\hline Yes & 4.1 & 8.8 & 4.1 & 2.6 & \multirow[t]{2}{*}{4.57} \\
\hline No & 95.9 & 91.2 & 117 & 97.4 & \\
\hline
\end{tabular}

Note. Class $1=$ high-severity developmental revictimization (DRV; $N=145$ ); Class $2=$ low-severity childhood/adolescence sexual abuse (CASA; $N=68$ ); Class $3=$ low-severity adulthood sexual assault (ASA; $N=122) ; \mathrm{NV}=$ nonvictims $(N=156)$. The sample size of American Indian or Native American was small $(N=12)$ and hence not included in the analysis.

adjusted residual variance is reported only if chi-square is significant.

${ }^{*} p<.05 .{ }^{* * * *} p<.001$

non-White) race, with a greater percentage of White women in the ASA class and a smaller percentage in the CASA class. Although the overall difference among the latent classes and the nonvictim group in the percentage of African American (vs. non-African American) women was significant, the adjusted residuals did not indicate a significant difference among the classes and the nonvictim group (see Table 4). No differences across the three latent classes and nonvictim groups were found for the other racial/ethnic backgrounds.

\section{Between-Group Differences in Emotion Regulation Difficulties}

The overall multivariate analysis of covariance (controlling for White vs. non-White race) examining differences between the three latent classes and the nonvictimized group on the six dimensions of emotion regulation difficulties was significant, Pillai's trace $=.17 ; F(18,1,449)=4.76, p<.001, \eta_{\mathrm{p}}^{2}=.06$. Follow-up univariate analyses of covariance revealed differences between latent classes and the nonvictimized group on all six dimensions of emotion regulation difficulties (see Table 5). Bonferroni-corrected pairwise comparisons provided support for the second hypothesis, as the DRV class reported greater difficulties in the specific dimensions of emotion regulation involving emotional clarity, the control of impulsive behaviors when distressed, and access to effective emotion regulation strategies than the ASA class, as well as greater deficits in emotional clarity than the CASA class (see Table 5). Finally, and providing partial support for the third hypothesis, all latent classes reported significantly greater difficulties in at least four specific emotion regulation dimensions than the nonvictimized group (see Table 5).

\section{Discussion}

The primary purpose of this study was to examine the presence of discrete classes of sexual victimization experiences during childhood/adolescence and adulthood among a racially diverse sample of women in emerging adulthood. An additional aim was to examine differences in dimensions of emotion regulation difficulties across the identified classes and a group of nonvictimized women. Consistent with both the first hypothesis and previous research, results revealed the presence of three latent classes corresponding to experiences of child/adolescent sexual abuse, adult sexual assault, and both (i.e., developmental revictimization; Black et al., 2011; Classen et al., 2005). On the basis of severity of victimization experiences and developmental period(s) in which they occurred, we labeled the three latent classes: DRV, CASA, and ASA. The use of person-centered analyses (i.e., LCA) to identify the presence of a specific DRV class corroborates existing research highlighting a robust association between childhood sexual abuse and experiences of sexual revictimization in female emerging adults (Classen et al., 2005; Walsh, Danielson, et al., 2012). These findings underscore the importance of identifying intervening risk and protective factors acting as mechanisms between childhood sexual abuse and adulthood sexual revictimization (e.g., risky sexual behavior, binge-drinking, and posttraumatic stress disorder; Messman-Moore \& Long, 2003) that could serve as potential points of intervention. In addition, the emergence of separate CASA and ASA classes is consistent with previous literature highlighting that revictimization is not an inevitable outcome of early sexual abuse, and conversely, that women with no experience of childhood sexual abuse are also vulnerable to initial victimization during adulthood (Black et al., 2011). These findings suggest the need for further research identifying both resilience factors that promote decreased risk for developmental revictimization among CSA survivors and risk factors for adulthood victimization among previously nonvictimized individuals.

Our second hypothesis was also supported, in that the DRV class reported greater difficulties than the CASA class on the dimension of emotion regulation involving emotional clarity, as well as greater difficulties than the ASA class on multiple dimen- 
Table 5

Univariate Effects, Estimated Mean Scores, and Pairwise Comparisons for the Six Dimensions of Emotional Regulation Difficulties Across the Three Latent Classes and the Nonvictimized Group

\begin{tabular}{|c|c|c|c|c|c|}
\hline Dimensions of difficulties in emotion regulation & Groups & $M(S E)$ & $F$ ratio & $\eta_{\mathrm{p}}^{2}$ & Pairwise comparisons \\
\hline Nonacceptance of emotional responses & $\begin{array}{l}\text { DRV } \\
\text { CASA } \\
\text { ASA } \\
\text { NV }\end{array}$ & $\begin{array}{l}14.35(.48) \\
14.50(.71) \\
12.53(.52) \\
10.34(.47)\end{array}$ & $14.74^{* * * * *}$ & .08 & DRV, CASA, ASA $>$ NV \\
\hline Difficulties engaging in goal-directed behavior when distressed & $\begin{array}{l}\text { DRV } \\
\text { CASA } \\
\text { ASA } \\
\text { NV }\end{array}$ & $\begin{array}{l}15.29(.41) \\
15.08(.60) \\
13.89(.45) \\
11.97(.40)\end{array}$ & $13.05^{* * *}$ & .08 & DRV, CASA, ASA > NV \\
\hline Difficulties controlling impulsive behaviors when distressed & $\begin{array}{l}\text { DRV } \\
\text { CASA } \\
\text { ASA } \\
\text { NV }\end{array}$ & $\begin{array}{r}12.90(.38) \\
11.78(.56) \\
10.93(.41) \\
8.79(.37)\end{array}$ & $21.40^{\text {**** }}$ & 2 & DRV $>$ ASA; DRV, CASA, ASA $>$ NV \\
\hline Limited access to effective emotion regulation strategies & $\begin{array}{l}\text { DRV } \\
\text { CASA } \\
\text { ASA } \\
\text { NV }\end{array}$ & $\begin{array}{l}18.65(.53) \\
17.18(.79) \\
16.30(.59) \\
12.75(.52)\end{array}$ & $22.15^{\text {**** }}$ & .12 & DRV $>$ ASA; DRV, CASA, ASA $>$ NV \\
\hline Lack of emotional awareness & $\begin{array}{l}\text { DRV } \\
\text { CASA } \\
\text { ASA } \\
\text { NV }\end{array}$ & $\begin{array}{l}14.46(.40) \\
12.98(.59) \\
13.23(.44) \\
11.94(.39)\end{array}$ & $6.74^{* * * *}$ & .04 & $\mathrm{DRV}>\mathrm{NV}$ \\
\hline Lack of emotional clarity & $\begin{array}{l}\text { DRV } \\
\text { CASA } \\
\text { ASA } \\
\text { NV }\end{array}$ & $\begin{array}{r}11.37(.30) \\
9.93(.45) \\
10.18(.33) \\
8.61(.29)\end{array}$ & $14.30^{\text {**** }}$ & .08 & DRV $>$ CASA, ASA, NV; ASA $>$ NV \\
\hline
\end{tabular}

Note. $\quad$ DRV $=$ high-severity developmental revictimization $($ Class $1 ; N=145) ;$ CASA $=$ low-severity child/adolescent sexual abuse $($ Class $2 ; N=68)$; ASA $=$ low-severity adulthood sexual assault (Class $3 ; N=122) ; \mathrm{NV}=$ nonvictims $(N=156)$. Pairwise comparisons were conducted using the Bonferroni correction term $(\alpha=.003)$.

****: $p<.001$.

sions of emotion regulation involving the control of impulsive behaviors when distressed, access to emotion regulation strategies, and emotional clarity. Furthermore, and providing partial support for the third hypothesis, all latent classes reported greater difficulties than the nonvictimized group on the dimensions of emotion regulation involving emotional acceptance, clarity, and the control of behaviors (both impulsive and goal directed) when distressed.

Findings suggest more severe victimization characteristics among women in the DRV class, compared with women exposed to victimization during a single developmental period. Specifically, a greater proportion of women in the DRV class reported experiencing penetrative abuse, and a longer duration of abuse during childhood/adolescence than women in the CASA class. These findings add to those of past studies suggesting significant differences in the physical severity and/or invasiveness of abuse as a function of developmental revictimization status, with revictimized women reporting more penetrative experiences than victims of childhood sexual abuse alone (U.S. college sample, Arata, 2000; Danish clinical sample, Lau \& Kristensen, 2010). Similarly, women in the DRV class reported more injury/physical pain as a result of adulthood sexual assault than women in the ASA class. These findings are consistent with past research indicating more severe adulthood victimization experiences (including use of physical force) among women with versus without a history of childhood sexual abuse (Messman-Moore \& Long, 2000). The findings of more severe victimization experiences among women in the DRV class (in conjunction with the failure to find evidence of a class characterized by developmental revictimization experiences but low severity) extend past literature on the link between severity of sexual victimization experiences and revictimization by using a person-centered, LCA approach. Further research is needed to examine the specific ways in which adulthood victimization experiences differ between women with and without a history of previous sexual victimization in childhood, as well as the potential factors contributing to more severe adulthood victimization among women with a history of childhood sexual abuse.

As noted previously, findings also provided support for the second hypothesis, as women in the DRV class (characterized by both more severe victimization and victimization across two developmental periods) reported significantly greater emotion regulation difficulties in three domains than women in the ASA class, and significantly greater deficits in emotional clarity relative to women in the CASA class. These findings are consistent with past research suggesting a cumulative impact of victimization on emotion regulation difficulties (Walsh et al., 2011). Results provide further support for the premise that early experiences of maltreatment may disrupt the development of adaptive emotion regulation strategies (Cicchetti et al., 1991) in ways that linger into adulthood. In fact, emotion dysregulation has been identified as one mechanism leading to sexual revictimization among individuals with histories of childhood sexual abuse (Walsh, Gonsalves, Scalora, King, \& Hardyman, 2012). No significant differences in any dimensions of emotion regulation difficulties emerged between the CASA and ASA classes. This finding may reflect the lower severity of victimization experiences of women in both these groups relative to the DRV class is consistent with past research 
highlighting the particular relevance of victimization severity (vs. simply the presence of victimization experiences) to psychopathology and distress (Charak \& Koot, 2015; Clemmons, Walsh, DiLillo, \& Messman-Moore, 2007) via the pathway of emotion dysregulation (Messman-Moore et al., 2013). In the current study, owing to the characteristics of the DRV class and its inclusion of women with more severe childhood and adulthood victimization experiences (relative to the other two classes), both the CASA and ASA classes were characterized by less severe victimization experiences, which may explain their comparable relations to emotion regulation difficulties. Nonetheless, when compared with women who did not report any experiences of sexual victimization, all three latent classes were higher on at least four dimensions of emotion regulation difficulties. These findings suggest that the observed between-group differences in emotion regulation difficulties were primarily driven by differences between women in any of the latent classes versus those without a history of victimization, and between women in the DRV class versus all other groups.

\section{Limitations and Implications for Future Research}

The findings presented here should be considered in the context of study limitations. First, the current findings are based on a cross-sectional design and, thus, preclude conclusions as to the precise nature and direction of the relation between sexual victimization and emotion dysregulation. Indeed, it is likely that this relation is bidirectional in nature, with victimization resulting in greater emotion dysregulation and emotion dysregulation increasing the risk for later revictimization. Future prospective studies are needed to clarify the precise relations between victimization and emotion dysregulation over time and across the life span. Second, lifetime sexual victimization was assessed via self-report measures, which introduce the potential for biased responding due to the inability to recall these experiences (Widom \& Morris, 1997). Nonetheless, when behaviorally specific questions about sexual victimization experiences are used to assess victimization (as done in the present study), the accuracy of reporting has been found to increase (Fricker, Smith, Davis, \& Hanson, 2003). Third, the present study did not take into consideration the impact of repeated sexual victimization occurring in a single developmental period on emotion regulation difficulties. Future studies should focus on investigating the differential consequences and correlates of developmental revictimization as conceptualized here (i.e., victimization across two or more developmental periods) and repeated victimization within a single developmental period. Such research would help clarify the best method for investigating sexual revictimization. Fourth, we did not account for the impact of other co-occurring abuse or neglect experiences. Doing so would yield a more comprehensive understanding of women's victimization experiences, which, in turn, may facilitate a better understanding of the pathways through which victimization experiences-together and separately - may relate to distress and psychopathology. Future research using a larger sample with higher rates of more severe victimization is needed to examine this question. This would yield important information regarding the specificity or generality of cumulative victimization and its impact on dimensions of emotion dysregulation.

\section{Clinical and Policy Implications}

The present investigation of lifetime sexual victimization characteristics in a community sample of emerging adult women yielded three discrete classes corresponding to the presence of childhood sexual abuse, adult sexual victimization, and sexual revictimization across developmental periods. The finding of a relatively higher prevalence of penetrative abuse during childhood among women with developmental revictimization (DRV class) suggests that preventative strategies should be directed toward child victims of rape in particular. In addition, findings suggesting the presence of an adulthood-only victimization class highlight the potential utility of primary prevention programs targeting key developmental tasks of emerging adulthood (Arnett, 2000), such as dating and more serious intimate relationships. Finally, findings highlight the need for targeted interventions aimed at improving emotion regulation and interpersonal functioning (Cloitre, Koenen, Cohen, \& Han, 2002; McDonagh et al., 2005) among women with a history of severe childhood sexual abuse and/or developmental revictimization.

\section{References}

Allen, B. (2008). An analysis of the impact of diverse forms of childhood psychological maltreatment on emotional adjustment in early adulthood. Child Maltreatment, 13, 307-312. http://dx.doi.org/10.1177/ 1077559508318394

Arata, C. M. (2000). From child victim to adult victim: A model for predicting sexual revictimization. Child Maltreatment, 5, 28-38. http:// dx.doi.org/10.1177/1077559500005001004

Arnett, J. J. (2000). Emerging adulthood. A theory of development from the late teens through the twenties. American Psychologist, 55, 469480. http://dx.doi.org/10.1037/0003-066X.55.5.469

Bernstein, D. P., Stein, J. A., Newcomb, M. D., Walker, E., Pogge, D., Ahluvalia, T., . . Z Zule, W. (2003). Development and validation of a brief screening version of the Childhood Trauma Questionnaire. Child Abuse \& Neglect, 27, 169-190. http://dx.doi.org/10.1016/S01452134(02)00541-0

Black, M. C., Basile, K. C., Breiding, M. J., Smith, S. G., Walters, M. L., Merrick, M. T., . . . Stevens, M. R. (2011). The National Intimate Partner and Sexual Violence Survey (NISVS): 2010 summary report. Atlanta, GA: National Center for Injury Prevention and Control, Centers for Disease Control and Prevention.

Calkins, S. D., \& Howse, R. B. (2004). Individual differences in selfregulation. Implications for childhood adjustment. In P. Philippot \& R. S. Feldman (Eds.), The regulation of emotion (pp. 307-332). Mahwah, NJ: Erlbaum Publishers.

Charak, R., \& Koot, H. M. (2015). Severity of maltreatment and personality pathology in adolescents of Jammu, India: A latent class approach. Child Abuse and Neglect, 50, 56-66. http://dx.doi.org/10.1016/j.chiabu .2015.05.010

Cicchetti, D., Ganiban, J., \& Barnett, D. (1991). Contributions from the study of high-risk populations to understanding the development of emotion regulation. In J. Garber \& K. A. Dodge (Eds.), The development of emotion regulation and dysregulation (pp. 15-48). Cambridge, United Kingdom: Cambridge University Press. http://dx.doi.org/10 $.1017 /$ CBO9780511663963.003

Classen, C. C., Palesh, O. G., \& Aggarwal, R. (2005). Sexual revictimization: A review of the empirical literature. Trauma, Violence and Abuse, 6, 103-129. http://dx.doi.org/10.1177/1524838005275087

Clemmons, J. C., Walsh, K., DiLillo, D., \& Messman-Moore, T. L. (2007). Unique and combined contributions of multiple child abuse types and 
abuse severity to adult trauma symptomatology. Child Maltreatment, 12, 172-181. http://dx.doi.org/10.1177/1077559506298248

Cloitre, M., Koenen, K. C., Cohen, L. R., \& Han, H. (2002). Skills training in affective and interpersonal regulation followed by exposure: A phasebased treatment for PTSD related to childhood abuse. Journal of Consulting and Clinical Psychology, 70, 1067-1074. http://dx.doi.org/10 .1037/0022-006X.70.5.1067

Cole, P. M., Michel, M. K., \& Teti, L. O. (1994). The development of emotion regulation and dysregulation: A clinical perspective. Monographs of the Society for Research in Child Development, 59, 73-100. http://dx.doi.org/10.2307/1166139

DiLillo, D., Fortier, M. A., Hayes, S. A., Trask, E., Perry, A. R., MessmanMoore, T., ... Nash, C. (2006). Retrospective assessment of childhood sexual and physical abuse: A comparison of scaled and behaviorally specific approaches. Assessment, 13, 297-312. http://dx.doi.org/10 $.1177 / 1073191106288391$

DiLillo, D., Hayes-Skelton, S. A., Fortier, M. A., Perry, A. R., Evans, S. E., Messman Moore, T. L., . . Fauchier, A. (2010). Development and initial psychometric properties of the Computer Assisted Maltreatment Inventory (CAMI): A comprehensive self-report measure of child maltreatment history. Child Abuse and Neglect, 34, 305-317. http://dx.doi.org/ 10.1016/j.chiabu.2009.09.015

Fowler, J. C., Charak, R., Elhai, J. D., Allen, J. G., Frueh, B. C., \& Oldham, J. M. (2014). Construct validity and factor structure of the difficulties in emotion regulation scale among adults with severe mental illness. Journal of Psychiatric Research, 58, 175-180. http://dx.doi.org/10.1016/j .jpsychires.2014.07.029

Fricker, A. E., Smith, D. W., Davis, J. L., \& Hanson, R. F. (2003). Effects of context and question type on endorsement of childhood sexual abuse. Journal of Traumatic Stress, 16, 265-268. http://dx.doi.org/10.1023/A: 1023748124626

Gratz, K. L., Bornovalova, M. A., Delany-Brumsey, A., Nick, B., \& Lejuez, C. W. (2007). A laboratory-based study of the relationship between childhood abuse and experiential avoidance among inner-city substance users: The role of emotional nonacceptance. Behavior Therapy, 38, 256-268. http://dx.doi.org/10.1016/j.beth.2006.08.006

Gratz, K. L., \& Roemer, L. (2004). Multidimensional assessment of emotion regulation and dysregulation: Development, factor structure, and initial validation of the difficulties in emotion regulation scale. Journal of Psychopathology and Behavioral Assessment, 26, 41-54. http://dx.doi .org/10.1023/B:JOBA.0000007455.08539.94

Gratz, K. L., Weiss, N. H., \& Tull, M. T. (2015). Examining emotion regulation as an outcome, mechanism, or target of psychological treatments. Current Opinion in Psychology, 3, 85-90. http://dx.doi.org/10 .1016/j.copsyc.2015.02.010

Humphrey, J. A., \& White, J. W. (2000). Women's vulnerability to sexual assault from adolescence to young adulthood. Journal of Adolescent Health, 27, 419-424. http://dx.doi.org/10.1016/S1054-139X(00) 00168-3

John, O. P., \& Gross, J. J. (2004). Healthy and unhealthy emotion regulation: Personality processes, individual differences, and life span development. Journal of Personality, 72, 1301-1334. http://dx.doi.org/10 $.1111 / \mathrm{j} .1467-6494.2004 .00298 . x$

Kaplow, J. B., \& Widom, C. S. (2007). Age of onset of child maltreatment predicts long-term mental health outcomes. Journal of Abnormal Psychology, 116, 176-187. http://dx.doi.org/10.1037/0021-843X.116.1.176

Lau, M., \& Kristensen, E. (2010). Sexual revictimization in a clinical sample of women reporting childhood sexual abuse. Nordic Journal of Psychiatry, 64, 4-10. http://dx.doi.org/10.3109/08039480903191205

Lo, Y., Mendell, N., \& Rubin, D. (2001). Testing the number of components in a normal mixture. Biometrika, 88, 767-778. http://dx.doi.org/ 10.1093/biomet/88.3.767
Macy, R. J. (2008). A research agenda for sexual revictimization: Priority areas and innovative statistical methods. Violence Against Women, 14, 1128-1147. http://dx.doi.org/10.1177/1077801208322701

McDonagh, A., Friedman, M., McHugo, G., Ford, J., Sengupta, A., Mueser, K., . . Descamps, M. (2005). Randomized trial of cognitivebehavioral therapy for chronic posttraumatic stress disorder in adult female survivors of childhood sexual abuse. Journal of Consulting and Clinical Psychology, 73, 515-524. http://dx.doi.org/10.1037/0022-006X .73 .3 .515

McLachlan, G. J., \& Peel, D. (2000). Finite mixture models. New York, NY: Wiley. http://dx.doi.org/10.1002/0471721182

Mennen, F. E., \& Meadow, D. (1994). A preliminary study of the factors related to trauma in childhood sexual abuse. Journal of Family Violence, 9, 125-142. http://dx.doi.org/10.1007/BF01531959

Messman-Moore, T. L., \& Long, P. J. (2000). Child sexual abuse and revictimization in the form of adult sexual abuse, adult physical abuse, and adult psychological maltreatment. Journal of Interpersonal Violence, 15, 489-502. http://dx.doi.org/10.1177/088626000015005003

Messman-Moore, T. L., \& Long, P. J. (2003). The role of childhood sexual abuse sequelae in the sexual revictimization of women: An empirical review and theoretical reformulation. Clinical Psychology Review, 23, 537-571. http://dx.doi.org/10.1016/S0272-7358(02)00203-9

Messman-Moore, T. L., Long, P. J., \& Siegfried, N. J. (2000). The revictimization of child sexual abuse survivors: An examination of the adjustment of college women with child sexual abuse, adult sexual assault, and adult physical abuse. Child Maltreatment, 5, 18-27. http:// dx.doi.org/10.1177/1077559500005001003

Messman-Moore, T. L., Walsh, K. L., \& DiLillo, D. (2010). Emotion dysregulation and risky sexual behavior in revictimization. Child Abuse and Neglect, 34, 967-976. http://dx.doi.org/10.1016/j.chiabu.2010.06 .004

Messman-Moore, T. L., Ward, R. M., \& Zerubavel, N. (2013). The role of substance use and emotion dysregulation in predicting risk for incapacitated sexual revictimization in women: Results of a prospective investigation. Psychology of Addictive Behaviors, 27, 125-132. http://dx.doi .org/10.1037/a0031073

Muthén, B., \& Muthén, L. (2013). Mplus (version 7.11). Los Angeles, CA: Authors.

Navalta, C. P., Polcari, A., Webster, D. M., Boghossian, A., \& Teicher, M. H. (2006). Effects of childhood sexual abuse on neuropsychological and cognitive function in college women. The Journal of Neuropsychiatry and Clinical Neurosciences, 18, 45-53. http://dx.doi.org/10.1176/ jnp.18.1.45

Nylund, K., Asparouhov, T., \& Muthén, B. (2007). Deciding on the number of classes in latent class analysis and growth mixture modeling: A Monte Carlo simulation study. Structural Equation Modeling: An Interdisciplinary Journal, 14, 535-569. http://dx.doi.org/10.1080/ 10705510701575396

Ramaswamy, V., DeSarbo, W. S., Reibstein, D. J., \& Robinson, W. T. (1993). An empirical pooling approach for estimating marketing mix elasticities with PIMS data. Marketing Science, 12, 103-124. http://dx .doi.org/10.1287/mksc.12.1.103

Ruggiero, K. J., McLeer, S. V., \& Dixon, J. F. (2000). Sexual abuse characteristics associated with survivor psychopathology. Child Abuse and Neglect, 24, 951-964. http://dx.doi.org/10.1016/S0145-2134 (00)00144-7

Schwarz, G. (1978). Estimating the dimension of a model. Annals of Statistics, 6, 461-464. http://dx.doi.org/10.1214/aos/1176344136

Sclove, L. (1987). Application of model-selection criteria to some problems in multivariate analysis. Psychometrika, 52, 333-343. http://dx.doi .org/10.1007/BF02294360

Steel, J., Sanna, L., Hammond, B., Whipple, J., \& Cross, H. (2004). Psychological sequelae of childhood sexual abuse: Abuse-related char- 
acteristics, coping strategies, and attributional style. Child Abuse and Neglect, 28, 785-801. http://dx.doi.org/10.1016/j.chiabu.2003.12.004

Walsh, K., Danielson, C. K., McCauley, J. L., Saunders, B. E., Kilpatrick, D. G., \& Resnick, H. S. (2012). National prevalence of PTSD among sexually revictimized adolescent, college, and adult household-residing women. Archives of General Psychiatry, 6, 935-942. http://dx.doi.org/ 10.1001/archgenpsychiatry.2012.132

Walsh, K., DiLillo, D., \& Scalora, M. J. (2011). The cumulative impact of sexual revictimization on emotion regulation difficulties: An examination of female inmates. Violence Against Women, 17, 1103-1118. http:// dx.doi.org/10.1177/1077801211414165

Walsh, K., Gonsalves, V. M., Scalora, M. J., King, S., \& Hardyman, P. L. (2012). Child maltreatment histories among female inmates reporting inmate on inmate sexual victimization in prison: The mediating role of emotion dysregulation. Journal of Interpersonal Violence, 27, 492-512. http://dx.doi.org/10.1177/0886260511421670

Widom, C. S., \& Morris, S. (1997). Accuracy of adult recollections of childhood victimization, Part 2: Childhood sexual abuse. Psychological Assessment, 9, 34-46. http://dx.doi.org/10.1037/1040-3590.9.1.34

Received June 10, 2016

Revision received July 28, 2017

Accepted August 9, 2017 